\title{
GUANABACOA COMO UNA "EXPERIENCIA" INDIA EN NUESTRA COLONIZACIÓN: LOS RETOS DE LA ARQUEOLOGÍA PÚBLICA
}

\author{
Lourdes S. Domínguez*
}

\begin{abstract}
Resumen: El artículo trata de la experiencia indígena de Guanabacoa, Cuba, asentamiento de principios de la colonización ibérica en el Caribe. Las cuestiones de la etnicidad y de la participación de la comunidad en la interpretación arqueológica muestran como una mirada a partir de la Arqueología Pública puede ser original y constructiva.
\end{abstract}

Palabras-clave: indígenas; Guanabacoa; colonización.

\section{Introducción}

Cuba fue la primera de las Islas de las Antillas Mayores en descubrirse, pero también la última en ser colonizada; cuando los españoles llegaron a nuestras costas habían experimentado, en gran medida, diferentes métodos de colonización, tanto en las tierras reconquistadas en el sur de España como en las Islas Canarias. (Colectivo autoral, 1994.)

De la Factoría pensada por Colón se pasó con rapidez a la Colonia por poblamiento, organizándose de esta manera a los grupos autóctonos para el trabajo en una forma que al inicio se llamó "encomienda", este sistema concebido en la Metrópoli pudo ser medianamente ideal en un primer momento, y en apariencias era humano y necesario, por el cual sólo se pedía a los aborígenes que se catequizaran. En realidad fue una repartición de hombres para con ellos establecer una esclavitud encubierta.

* Oficina del Historiador, Havana, Cuba, chinopelon@gmail.com
Este método de aplicación dual se escudó en el mecanismo de la cristianización, mostrándolo como objetivo principal, recuérdese que España en ese momento era la campeona de la cristiandad, pero en verdad la única aspiración era organizar la población indígena para con ella abordar nuevos modos de laboreo, dándosele una apariencia legal a una cruel y despiadada explotación de su fuerza de trabajo.

Entre 1524 y 1555 se lleva a cabo la fase continental de la conquista y colonización de América, pero dentro de este período, en 1542 , se dictan las Leyes Nuevas y con ellas la abolición de las encomiendas, manifestándose la Corona sobre la misma, como obsoleta y contradictoria. Esto fue el resultado de las presiones ejercidas en la Corte a tal efecto, por esta razón España determinó ensayar otros procedimientos con resultados similares; surgió así el Plan de la Experiencia, y se escogió a Cuba para su primera puesta en escena.

Se adoptaron nuevas fórmulas para la creación de núcleos indígenas, ejemplificadas en los casos del Caney en Santiago de Cuba y de Guanabacoa en La Habana, para evitar 
su deambular por estas prominentes ciudades que a la sazón se disputaban la primacía de la Isla.

Lo acontecido en este proceso de conquista y colonización, a partir de los sistemas experimentados y aplicados, altera las normas y el equilibrio territorial e hizo bastante difícil el afán de reconcentrar de manera obligatoria a estos indios "vacos" 0 "vacantes" en reductos muy distintos a sus verdaderos pueblos (Ramos, 1992).

Para adentrarnos en el estudio del proceso de colonización en la Cuba del siglo XVI, la vía documental y bibliográfica deja en verdad muchas lagunas en la información, por eso consideramos como uno de los imperativos de la investigación arqueológica moderna, crear la estructura y la estrategia apropiada para la interpretación de estos eventos a partir de las evidencias materiales, logrando así definir con más claridad lo ocurrido con estos pueblos en ese momento histórico concreto.

De esta forma, y a partir de los conceptos de la Arqueología Histórica y de la Arqueología Pública (Funari 2001), es que debemos enfrentar la investigación en la actualidad. El estudio de este período de contacto y transculturación indohispánica a partir de los elementos de ambas culturas: aborigen (Robrahn-González 2000) y europea, es la línea conducente, pues los mismos perviven en dicho proceso a partir de criterios muy objetivos (Rives, Domínguez, Pérez, 1991).

\section{Encomiendas y experiencias}

El tratamiento hacia los indígenas de América fue para la política Real española de ese momento una actuación indecisa, los escrúpulos de tipo moral chocaban con los intereses económicos y se interrelacionaban con el proceso colonizador, al final vencieron los económicos.

A partir de 1503 se autoriza a todos los hombres que viajan al Nuevo Mundo, en vías de conquista y colonización, capturar a los indios cuando hiciesen resistencia, pero acto seguido se recuerda su carácter de "hombres libres por condición". La ambigüedad nutre la documentación y la realidad se manifiesta de una forma distinta. Son constantes las menciones a la "guerra justa" o a la "guerra buena" (Pichardo, 1984), y de hecho no existe una línea consecuente para tratar el asunto.

Así es realmente esclavizada la población autóctona, de una forma directa al principio y encubierta después, con la aplicación de sistemas como la encomienda.

Esta llamada encomienda se desarrolló en las Indias y fue concebida como un patronato de favor Real sobre una parte específica de los naturales de estas tierras, no era para todos los indios, ni se aplicaba a todos los concentrados en establecimientos cercanos a las posesiones del encomendero o a los centros urbanos incipientes, las famosas Villas.

Existía obligatoriedad por parte del encomendero español de instruir a los indios entregados en la religión cristiana y enseñarles los rudimentos esenciales, de la llamada vida civilizada al fiel de los europeos salidos del medioevo, así como defenderlos en sus personas y propiedades, a cambio se demandaba tributo en forma de trabajo, por considerarse privilegios las cosas que se les ofrecían (Franco, 1985).

En la práctica "... los encomendados eran algo así como siervos de los encomenderos", (Portuondo, 1953), pero en la realidad las encomiendas constituían una institución explotadora hasta límites insospechados del trabajo indígena, estos hombres fueron sometidos a un proceso de rápida desculturización. Las Leyes de Burgos son el principal soporte de este mecanismo diabólico.

En Cuba, en 1513 y mediante Cédula Real, el conquistador don Diego Velázquez de Cuéllar inició los repartimientos de indios para ejecutar las encomiendas. La experiencia acumulada en La Española, le permitió propiciar una política de entrega de indios a partir de familias, pueblos o comunidades aborígenes completas, pues de esta manera no se desarraigaban y se lograban mayores rendimientos productivos. 
Entre 1516 y 1519, fracasadas las tentativas hechas con las encomiendas, se propone por los frailes Jerónimos y en especial por Rodrigo de Figueroa en La Española, efectuar los famosos "experimentos" que pretendían determinar la capacidad intelectual y política de los indios para valorar por sí mismos, pero siempre a la manera española, la forma de vida más adecuada.

Este es un antecedente de las llamadas "experiencias indias" puestas en práctica en Cuba décadas más tarde y las cuales resultaron una manera inconsecuente utilizada por la Monarquía Española para intentar recuperar la productividad diezmada de las masas autóctonas.

El historiador L. Hanke (1950) definió a las "experiencias" como “... el último acto en el drama de los experimentos para liberar a los indios". El período de su implantación fue del 1525 al 1535, basándose siempre en la concentración de los aborígenes sin ubicación ni trabajo, llamados "vacos" o "vacantes", en pueblos artificiales donde siempre hubiere clérigos para "adoctrinarlos" y guiarlos en sus labores, de esta forma los tendrían cerca y a mano para cualquier menester.

Las autoridades de la isla de Cuba se niegan a aceptar este nuevo procedimiento, prohibiéndoselo a Pedro Mexía Trille, designado por el Rey a tal efecto.

Con posterioridad este hombre le propuso a la Corona que encargara al Obispo la conducción de la "experiencia" y así se fundó el primer pueblo de indios en Bayamo, al oriente de Cuba. Esta prueba resultó un fracaso, el Rey ordenó un segundo intento y para ello designó al teniente gobernador don Manuel de Rojas, quien en carta al Monarca le dice que al tratar de poner en práctica su orden cree: "...Ha de hacer poco fruto según la enemistad que esta gente tiene con la gente española, por el mal tratamiento que le tienen hecho, tanto por sus culpas como por las nuestras". (Chacón y Calvo, 1934.)

Se trató de hacer otro ensayo en San Juan de Puerto Rico en 1520 pero se infiere el fracaso al no existir referencia alguna (Chacón y Calvo, 1934). El éxito mediatizado de la proclamación de la libertad de los naturales a partir de las Leyes Nuevas en 1542 fue el segundo revés, porque estas jamás fueron aplicadas como estaban escritas y muy en especial por el rechazo de los colonos. Hasta 1553 no se pueden poner en práctica algunas soluciones que parafrasean estas susodichas leyes (Pichardo, 1984).

Con toda la práctica acumulada por las tentativas y frustraciones se piensa como solución al problema de estos indios sin dueño, trabajo ni ubicación, merodeadores por las ciudades y creadores de grandes disturbios, la idea de reconcentrarlos tomando algunas de las estipulaciones promulgadas por las Leyes Nuevas, fue una salida y de aquí renace el caso de Guanabacoa, esta región se comienza a organizar a partir de 1555, emplazándose en la cercanía de La Habana, en esa época la capital de Cuba.

\section{Estrategias de la Arqueología Pública}

La Arqueología Histórica permite abordar nuevas líneas de trabajo, así como pensar en nuevas propuestas fuera de los planteamientos clásicos para el estudio de estos sitios de transculturación. La estructuración de las diferentes estrategias de clasificación de evidencias materiales, tiene su referencia en los objetos exhumados que presentan simultáneamente rasgos indígenas hispanos en su morfología, ello requiere de trabajos de campo concebidos dentro de un enfoque mucho más ágil.

Los escasos documentos de esta época abogan también por una labor interdisciplinaria que agrupe etnólogos, arqueólogos e historiadores en la cual, el rol jugado por las evidencias materiales debe corresponder a la metódica arqueológica y al papel rector de estas investigaciones.

Tenemos como ejemplo clásico el sitio El Yayal como representante de la etapa de contacto y transculturación en Cuba, cuyo análisis y enfoque metodológico permitió considerarlo como un interesante estudio de caso. (Domínguez, 1984.) 
Para realizar este trabajo es imprescindible la definición de estrategias arqueológicas concretas a partir de dos versiones del evento:

a) Que el período de contacto está relacionado con la conquista y colonización y se puede considerar hasta mediados del siglo XVI.

b) Que el período de transculturación se puede efectuar desde el inicio del siglo $\mathrm{XVI}$ y en épocas posteriores de acuerdo con el desarrollo del proceso histórico de cada pueblo.

Para este primer momento, es válido utilizar el enfoque siguiente, sobre todo a la hora de analizar las evidencias. (Domínguez, 1980.)

a) Materiales en superficie que no presentan variación intrínseca ni huellas de uso y reuso.

b) Materiales de niveles estratigráficos definidos, con cambios intrínsecos y tienen evidencias de uso y rehúso.

c) Un producto nuevo, la creación hecha por estos grupos mediante la simbiosis cultural.

Puede ocurrir todo lo contrario en el enfoque del evento. Entendido a partirde 1550, las evidencias en este período reflejan cada vez menos los rasgos indohispánicos hallados y se pueden analizar de esta forma:

Objetos de procedencia europea.

Objetos de procedencia criolla bien definidos.

Objetos de procedencia aborigen.

A medida que pasa el tiempo los objetos indígenas serán cada vez más vestigiales, como ocurre con el ejemplo de Guanabacoa (Domínguez, 1989).

El paso de la inferencia directa obtenida a partir de los restos arqueológicos detectados hace posible su contrastación con los hechos históricos, hipotéticos o comprobados por documentos. Estas son las características fundamentales de las evidencias que se consideran imponderables en esta etapa de transculturación.
(Robrahn-González 2001). Por ejemplo, la presencia en los contextos arqueológicos de cerámica indígena o de mayólica novohispana, identifican respectivamente a un grupo aborigen agroalfarero y a un sitio colonial, quizás del siglo xvı, estas muestras resultan válidas para la contrastación del evento histórico específico, pero es preciso ser cuidadoso, pues no permiten ir mucho más allá, a no ser que se examinen los materiales a partir de asociaciones significativas, y estas permitan reconstruir hechos y cronologar con seguridad.

Grandes grupos de hallazgos de procedencia europea 0 de manufactura arahuaca antillana, ya sean de metal, loza, porcelana, cerámica 0 vidrio, presentes en un sitio arqueológico, pueden constituir de igual manera las huellas de un enclave europeo, de aborígenes españolizados, o de cimarrones, ya que en estos casos los objetos pudieron ser adquiridos de diversas formas, en el mercado, por robo, por trueque, etc. lo cual sería muy difícil de comprobar si no es a través de las relaciones significativas de las muestras entre sí y con otros elementos del contexto, o una posible existencia de documentación probatoria del evento.

Otros aspectos de la investigación, como son los rasgos valorativos, la proporción de los materiales en general y en específico de la cerámica y teniendo en cuenta las características del residuario, permitirán tener una idea concreta, de si es un lugar de vivienda, un comercio urbano o campesino, palenques, cementerios, u otro. Estos parámetros deben fijarse con preferencia en el hallazgo o en el estudio de la muestra que denote transculturación.

Las características particulares de las evidencias no deben ser criterios rectores que rijan la investigación arqueológica sino el intercambio con la documentación, si existe, o cualquier otro análisis como lo plantea la Arqueología Histórica, y sobre todo que permita la reconstrucción del evento, objetivo en sí de la investigación.

En cuanto a los métodos de excavación y rescate en estos contextos, debe realizarse 
preferente con estratigrafía natural, teniendo especial cuidado en el espesor de la capa antropogénica, la cual se infiere debe ser exigua, por lo general en Cuba esta capa fértil no rebasa los $0.25 \mathrm{~m}$, y matemáticamente nos da unos $5 \mathrm{~mm}$ por año suponiendo que el asentamiento sea de cincuenta años.

La excavación en estratos naturales en este tipo de sitios es bien difícil y exige gran atención y cuidado en la colecta de superficie, la que se cumplimentará por medio del sistema de cuadrículas, y aportará después mayores posibilidades para el procesamiento de los datos, teniendo en cuenta el aumento de la extensión del área para poder ver en planta la expansión del fenómeno y poderlo entender mucho más integralmente. En estos casos las excavaciones reducidas sólo permiten apreciar una pequeña parte de la verdad.

\section{Estudio de caso: Guanabacoa y sus usos públicos}

Las Actas Capitulares del Cabildo de La Habana acreditan la creación de un poblado de indios fomentado el 12 de junio de 1554 en un paraje llamado Guanabacoa y dice así: “...que en armonía con lo tratado con los dichos indios se le hagan un poblado, por que estando así juntos se podrá tener en cuenta y razón de ellos" (Vidal Cirera, 1887).

El afamado historiador Gerardo Castellanos (1948) plantea al respecto: “...ante la evidente situación decadente, degenerada más bien, y trashumante de los indios de esta región, se propusieron recoger a los mansos como a los rebeldes o jíbaros y concentrarlos donde ellos pudieran fomentar poblados, cultivar la tierra, establecer industria y vivir a su manera a condición de ciertas medidas u enseñanzas cristianas ...", lo que hizo que se convirtieran al tiempo, estos poblados en “... zonas de reducciones cual similares a corrales o presidios donde no hubo jamás propósito de enseñanza cristiana y nada más" (Castellanos, 1948).
Aunque el historiador Pezuela asegura que este pueblo de indios de Guanabacoa no lo será como tal hasta 1576, cuando se establece por documento y se alza en él una iglesia servida por la orden de San Francisco (Pezuela, 1868), hay referencias de que ya en 1530 los indios de esta zona son obligados a hacer "... sus conucos y granjerías" (Archivo Nacional de Cuba (ANC): Fondo Academia de la Historia (Donativo de Néstor Carbonell) AH - S - 715 - C - 441) y concentrarse para poder ser ubicados con mayor premura y certeza (Gómez, Rodríguez, 1991). Paralelo a esto va ocurriendo el fenómeno llamado desculturación (Ortiz, 1965) en las costumbres y prácticas tradicionales propias, consecuencia de la imposición de nuevas formas de comportamiento.

Es lógico que esto se refleje en la vida material como se deduce del siguiente documento donde se habla de los bastimentos que debe llevar un grupo “... un par de rallos de cobre e algún burén de cobre pequeños e cebucanes..." (ANC AH - S - 298 - C - 31) donde se puede comprobar un cambio sustancial en la práctica ancestral de producción de casabe, con el uso del metal en un artefacto que siempre fue de barro.

Otra modificación aún más significativa en la experiencia india de Bayamo se constata cuando se habla de los gastos de “... Doze pesos en oro en azadones y hachas para su labor" (ANC AH - S - 234 - C - 29), esto confirma la utilización de instrumentos de trabajo de hierro en la agricultura; válida es la referencia al hacha petaloide de hierro forjado aparecida en el sitio El Yayal, Holguín

(Domínguez, 1984). También podemos ver esta situación en el uso de armas como “...ballestas, lanzas y espadas", factibles de encontrar en los residuarios, al igual que herraduras, cadenas de estribo, estribos, cuchillos, y otros.

En lo concerniente al material cerámico, se confeccionan enseres utilitarios llamados de forma equívoca "cerámica negroide" cuando en realidad es un tipo de cerámica transicional o transculturada muy abundante en los sitios coloniales, hecha de una greda 
muy parecida a la utilizada por los aborígenes, algunas veces levantada a torno, otras a partir del "coiling" o levantado a mano y quemada en hornos cerrados de mayor intensidad, o simplemente en hornos abiertos.

A estos ceramios se les ha conocido por diferentes acepciones, entre ellas Colono Ware (Deagan, 1987), criolla (Rivera, 1992) y de transculturación (Domínguez, 1980).

Su presencia en los sitios habaneros es cuantiosa, en casi todas las excavaciones hechas en esta región resulta abundante, como ocurrió en Calvo de la Puerta (Domínguez 1980); incluso en Nicaragua, en el sitio León Viejo, hay una simbiosis que da posibilidad al surgimiento de una cerámica la cual puede llamarse de transculturación.

La documentación afirma la confección de este tipo de cerámica utilitaria en el sitio de Guanabacoa, donde hay referencias de su fábrica entrado el siglo XIX (Bremer, 1980).

Hay discrepancias entre los historiadores guanabacoenses acerca de las fechas de fundación de este poblado de indios y también se discute el hecho de que no había ningún enclave aborigen en el lugar con anterioridad, estos aspectos han sido muy debatidos pero al respecto no se ha dicho la última palabra (Gómez, Rodríguez, 1991) y se contraponen planteamientos simples como la información surgida cuando el ataque de Jacques de Sores en 1555, en que los habaneros se refugiaron de las iras del corsario francés en el poblado de Guanabacoa (Eguren, 1986; Acosta, 1988).

De acuerdo a lo expuesto de manera sistemática sobre la inexistencia de un poblado aborigen en Guanabacoa, pero con la certeza de que el lugar fue una "experiencia india o un pueblo de indios", decidimos excavar en ella, pues esta localidad fue concebida de todas formas en el siglo XVI, y de una forma u otra, siempre para indios y por indios. La hipótesis de su posible enclave inicial aborigen fue uno de nuestros objetivos, la estrategia trazada, partiendo de esta hipótesis anterior, propició y dio base a este estudio de caso.
Al retomar el análisis historiográfico de Guanabacoa se nos ofreció un panorama muy favorable según los planos realizados por el historiador Pedro Herrera (c.p. 1986), construidos con su vasta información y donde concibe y plasma la ubicación en todo este terreno de dos posibles focos de asentamiento indígena.

Estos lugares son La Loma del Indio en la actualidad calle Estrada Palma-, pero que antes tenía el nombre de Calle de los Indios, al noreste de Guanabacoa, al sur, junto al arroyo del mismo nombre, tenemos el área de Tarraco, asociada a las calles Corralfalso y Cruz Verde, conocidas hasta la actualidad. En ambos lugares la toponimia nos animaba a preestablecer la posibilidad de encontrar lo buscado (Domínguez, 1989).

Cuando la logística estuvo a punto, nos dimos a la tarea de realizar la primera fase de la investigación arqueológica: la prospección de las áreas de posible productividad, las mismas estaban urbanizadas y no existía ningún precedente de trabajo arqueológico sistematizado en la región, al inicio el rastreo nos llevó a situaciones muy complicadas, al estar tan utilizado el terreno la posibilidad de excavaciones eran bien escasas. En el intento, encontramos en las áreas escogidas numerosos inmuebles de bastante antigüedad, provistos de traspatios o patios aledaños, en los cuales por tradición oral familiar se decía que nunca se había construido y se podían considerar terrenos vírgenes.

Se realizó una nueva consulta de la documentación con la ayuda de Herrera y decidimos escoger los dos primeros sitios, uno en cada área preestablecida, tratando de contrastarlos entre sí y siguiendo los preceptos marcados por Pichardo Moya, en los asientos aborígenes de la loma y el río, y al efecto resultaron Guanabacoa 2 (Loma del Indio) y Guanabacoa 3 (Tarraco - Cruz Verde, que es un arroyo).

Durante los meses de mayo y junio de 1987 y de acuerdo a los pronósticos del tiempo (el suelo guanabacoense es muy propicio a la acumulación de agua por su activo manto freático) se comenzaron los 
movimientos de tierra, con el objetivo primordial de encontrar enclaves aborígenes y elementos de posible transculturación. Otro de los objetivos era calcular, con los materiales exhumados, el tiempo de estancia y el probable desarrollo socioeconómico del grupo o grupos humanos emplazados allí.

Se excavó sistemáticamente en ambos lugares y en los dos cortes se llegó al sustrato estéril, moviendo unos $20 \mathrm{~m}^{3}$ de tierra antropogénica. Las exhumaciones resultaron fértiles en todas sus capas y fueron controladas con rigor para su posterior estudio de laboratorio.

Los cortes se planearon en escaques de $2.50 \mathrm{~m} \times 2.50 \mathrm{~m}$, divididos en cuatro secciones cada uno. En Guanabacoa 2 se planearon cinco escaques pero sólo se excavaron tres, y en Guanabacoa 3 se cortaron los dos previstos. El sistema metodológico utilizado al inicio y dadas las circunstancias de revoltura del terreno fue la estratigrafía artificial, en capas de $5 \mathrm{~cm}$. A partir de los perfiles se hizo una prueba de cortes por capas naturales, las cuales estaban hasta cierto punto bien definidas, este sistema lo habíamos puesto en práctica en Nicaragua, en el sitio León Viejo en 1982 y nos había dado muy buen resultado. (Domínguez, 1993.)

El trabajo arqueológico con capas artificiales primero y naturales después permitió un estudio de frecuencia en el propio campo, que brindó información para tomar decisiones en la orientación de los cortes. La profundidad osciló en todos los casos entre los 0.00 y $1.00 \mathrm{~m}$. Las evidencias se comportaron con bastante abundancia. Todos los cortes resultaron ser polivalentes, debido a la densidad y variedad de evidencias de la vida material de los hombres, que en el decursar del tiempo, se asentaron en ella y sus inmediaciones.

Terminado el trabajo de campo en estas jornadas, se pasó a la investigación de laboratorio, cuyo resultado demostró que no habíamos encontrado los enclaves aborígenes iniciales, aunque si pudimos observar en el sustrato antropogénico huellas fehacientes de la presencia indígena de grupos agroalfareros, ellos debieron asentarse en estas áreas y por lógica, no se debía descartar una posibilidad de estancia prefundación como pueblo de indios, esto puede ser acuñado por la frecuencia de cerámica aborigen en sus formas comunes de ollas y burenes (Domínguez, en Gómez y Rodríguez, 1991).

Nuestro objetivo, como hemos dicho, era buscar los primeros asentamientos aborígenes, pero en realidad debemos consignar, que sin querer, encontramos innumerables elementos de la cultura africana unidos al sustrato inicial de este pueblo, con hallazgos como cuentas de collares, azabaches, etc., relacionados en su gran mayoría, de alguna manera, con el desarrollo de sus creencias religiosas y la parafernalia usada por los Cabildos y otras instituciones de los cultos afrocubanos.

Quedó bien esclarecido, a partir de los artefactos hallados, que estábamos ante un sitio donde el proceso de transculturación se había desarrollado, fueron exhumados instrumentos líticos realizados en el rehúso de piedras de fusil o pedernal (Rives, Febles, Domínguez, 1989) y también en una lámina gruesa de cristal blanco, posiblemente de un vaso del siglo xıx, trabajada con una tipología de tallado muy similar a las encontradas en 1986 en el sitio Laguna de Algodones, en la ciudad de Trinidad, al sur de Cuba (Febles, Domínguez, 1987). Estos objetos, de tan importante factura, fueron encontrados en el sitio G - 3 (Calle Cruz Verde) junto a otros elementos también valiosos, ello permitió la planificación de una cuarta excavación en las cercanías de esta calle y que será objeto de estudios posteriores.

La cerámica con su capacidad diagnóstica, se presentó en ambos cortes, las muestras se ubicaron cronológicamente en una amplia línea de tiempo, por ejemplo encontramos tiestos de los siglos XVI y XVII con ceramios torneados como botijuelas, cazuelas, así como pastas porosas vidriadas con estaño y plomo, sin lugar a dudas mayólicas. Se presenta muy abundante la 
cerámica roja burda con o sin barniz de plomo, siempre en vajillas utilitarias o de cocina, lo que suele llamarse Morro Ware (Deagan, 1987).

En cuanto a la gama de porcelanas y semiporcelanas aparecen restos en una frecuencia limitada, muy fragmentados y con poca posibilidad de reconstruir las formas, aunque permiten apreciar la existencia de diferentes tipologías que van desde la porcelana china de los siglos XVI y XVII hasta la inglesa del XIX.

Debemos hacer notar la aparición de diferentes objetos rehechos a partir de desperdicios de otros materiales, un ejemplo son las fichas para jugar y sumergidores de redes hechos de la cerámica mayólica, realizados en este material por su docilidad, similares se han encontrado en algunas excavaciones de la Habana Vieja, especialmente en el sitio Calvo de la Puerta (Domínguez, 1984) y en Puerto Rico, en las excavaciones efectuadas en el antiguo Cuartel de Ballajá, en el viejo San Juan (Rivera, 1992).

También el vidrio se consideró uno de los materiales más abundantes, sobre todo botellas de vino $u$ otras bebidas pertenecientes al siglo XIX, así como vasos y copas. También hay gran cantidad de enseres de hueso y una buena muestra de restos de dieta.
Nuestra hipótesis de trabajo señala la posibilidad de que en este lugar hubiera existido un asiento inicial aborigen, es posible de la etnia arahuaca, esto no pudo confirmarse cabalmente, pero en cambio muchos de los artefactos encontrados en ambos cortes indican con certeza el desarrollo en los mismos del evento de la transculturación, permitiendo esclarecer algunas de las incógnitas manejadas, así mismo esta investigación posibilitó el acopio de elementos para el estudio de la etapa sociológica de la transculturación en un nuevo lugar de Cuba, y sobre todo esclarecer puntos sobre los pueblos de indios, como el que estamos seguros existió en Guanabacoa.

\section{Agradecimientos}

Soy muy agradecida al apoyo de la Fundação de Apoio à Pesquisa do Estado de São Paulo, FAPESP, pues fue gracias al esa apoyo que he desarrollado esta investigación, desarrollada en el Núcleo de Estudos Estratégicos (NEE), Universidade Estadual de Campinas, Brasil, así como de la Oficina del Historiador de La Habana, Cuba y de la Academia de Ciencias de Cuba. Como profesora invitada, he trabajado con el profesor Pedro Paulo A Funari, a quién soy agradecida especialmente.

\begin{abstract}
Native indigenous peoples at Guanabacoa, Cuba, an early I berian colonial settlement in the Caribbean. Issues relating to ethnicity and the participation of local peopla in the archaeological interpretation show that a public archaeological approach may be innovative and forward looking.
\end{abstract}

Key-words: natives; Guanabacoa; colonization. 


\section{Bibliografía}

ACOSTA, A.

1988 "La villa que jamás se fundó", en Gramma, La Habana, mes de diciembre, p. 4 [s.o.d.].

BREMER, F.

1980 Cartas desde Cuba, Editorial Arte y Literatura, La Habana.

CASTELLANOS, G.

1948 Relicario histórico. Frutos coloniales de la vieja Guanabacoa, Editorial Librería Selecta, La Habana.

CHACÓN Y CALVO, J. M.

1934 La "experiencia del Indio" [s. n.], Madrid. COLECTIVO AUTORAL

1994 Historia de Cuba. La colonia. Evolución socioeconómica y formación nacional, desde los orígenes hasta 1867, Instituto de Historia de Cuba, Editora Política, t. I, La Habana.

DEAGAN, K.

1987 Artifacts of Spanish Colonies of Florida and the Caribbean, 1500-1800, Smithsonian Institution Press, vol. I, Washington. DC.

DOMÍNGUEZ, L.

1980 "Cerámica transcultural en el sitio Colonial Casa de la Obrapía", en Cuba Arqueológica II, Editorial Oriente, Santiago de Cuba.

1984 Arqueología Colonial de Cuba: dos estudios, Editorial de Ciencias Sociales, La Habana.

1987 "Arqueología de Guanabacoa", en Carta Informativa, no. 96, II época, Centro de Antropología, La Habana.

1989 "Guanabacoa: raíces indígenas", ponencia en Primer Coloquio de Historiadores Locales Guanabacoa en la Historia, celebrado en el Municipal de Cultura de Guanabacoa, La Habana (inédito).

1993 Prospecciones sistemáticas en León Viejo. León Viejo: Pompeya de América, Instituto Nicaragüense de Cultura, UNESCO, Managua.

EGUREN, G.

1986 La fidelísima Habana, Editorial Letras Cubanas, La Habana.

FEBLES, J. Y L. DOMÍNGUEZ

1987 "Herramientas de vidrio en un sitio arqueológico agroalfareros tardío en la Provincia de Sancti Spíritus", Reporte de Investigación, no. 7, Instituto de Ciencias Sociales, Editorial Academia, ACC, La Habana.

FRANCO, J. L.

1985 Apuntes para una historia de la legislación y administración colonial en Cuba. (15111800), Editorial de Ciencias Sociales, La Habana.
FUNARI, P. P. A.

2001 Public archaeology from a Latin American perspective. Public Archaeology, Londres, v. 1, p. 239-243,

GÓMEZ, M. Y M. RODRÍGUEZ

1991 La fundación de Guanabacoa, noticias históricas, Boletín del Museo Municipal de Guanabacoa, La Habana.

HANKE, L.

1950 "Los primeros experimentos sociales en América", en Revista Bimestre Cubana, Vol. LXV, La Habana

ORTIZ, F.

1965 Contrapunteo cubano del tabaco y el azúcar, Consejo Nacional de Cultura, La Habana.

PEZUELA, J. DE LA

1868 Historia de la Isla de Cuba, Editorial Carlos Bailly - Baillere, t. I, Madrid.

PICHARDO, H.

1984 Las ordenanzas antiguas para los indios. Las leyes de Burgos de 1512, Editorial de Ciencias Sociales, La Habana

PORTUONDO, F.

1953 Historia de Cuba, Editorial Minerva, La Habana.

RAMOS, L. J.

1992 “El 'libro copiador' de Cristóbal Colón como fuente para el conocimiento de las relaciones mantenidas entre españoles y taínos en la Navidad entre diciembre 1492 a noviembre de 1943", en Memorias del Congreso de Historia del Descubrimiento, t. I, Santo Domingo.

RIVERA, V.

1992 "Proyecto Ballajá", Informe depositado en Instituto de Cultura Puertorriqueña, San Juan (inédito).

RIVES, A., J. FEBLES Y L. DOMÍNGUEZ

1989 "Artefactos de piedra tallada en el pueblo indio de Guanabacoa en los siglos XVI y XVII", Simposio de la Cultura de la Ciudad de La Habana, La Habana (folleto).

RIVES, A., L. DOMÍNGUEZ Y M. PÉREZ

1991 "Los documentos históricos sobre las Encomiendas y la Experiencia indias de Cuba, y las evidencias arqueológicas del proceso indohispánico", en Estudios Arqueológicos, Editorial Academia, La Habana.

ROBRAHN-GONZÁLEZ, E. M.

2000 Reflexionen ueber den Gedrauch der historischen Analogie in Brasilien.. A. Gramsch (ed.) Vergleichen als archaelogische Methode. Analogien in den Archaelogien, 
BAR International Series, arbeitsgemeinschaft Theorie (T-AG).

ROBRAHN-GONZÁLEZ, E. M.

2001 El uso de la Analogia en la Etnoarqueologia Brasileña. Anais da II Reunión Internacional de Teoria Arqueológica en América del Sur.

VIDAL CIRERA, F.

1887 Historia de la villa de Guanabacoa, Imprenta Universal, La Habana.

\section{Entrevistas}

HERRERA, P.

1986 Comunicación personal. Historia de Guanabacoa.

\section{Fuentes primarias}

\author{
ANC: Fondo Academia de la Historia, donativo \\ Néstor Carbonell. \\ $\mathrm{AH}-\mathrm{S}-715$ - C - 441 \\ $\mathrm{AH}-\mathrm{S}-298-\mathrm{C}-31$ \\ $\mathrm{AH}-\mathrm{S}-234-\mathrm{C}-29$
}

